\title{
Effectiveness of the Remedial Courses on Improving EFL/ESL Students' Performance at University Level in the Arab World
}

\author{
Fadel H. M. Al Othman ${ }^{1} \&$ Khaled M. Shuqair ${ }^{1}$ \\ ${ }^{1}$ The Public Authority for Applied Education and Training (PAAET), College of Basic Education, English Language \\ Department, Kuwait \\ Correspondence: Fadel H. M. Al Othman, The Public Authority for Applied Education and Training (PAAET), \\ College of Basic Education, English Language Department, Kuwait. E-mail: fadel_osman@hotmail.com
}

Received: July 8, 2013

Accepted: July 25, 2013

Online Published: August 6, 2013

doi:10.5430/ijhe.v2n3p132

URL: http://dx.doi.org/10.5430/ijhe.v2n3p132

\begin{abstract}
Many hypotheses have been passed by professors in the language teaching profession concerning the effects of remedial courses in enhancing the skills of students in the English language. Most people share the sentiment that remedial courses are quests in vain when it gets to improving the skills of students learning English as a first or second language (EFL/ESL). Others claim that the teaching strategy is the key to attaining the positive results in students taking remedial courses. This research looks into evidence presented by other researchers about the effectiveness of remedial courses. The research material used is mainly secondary. Through a comprehensive exploration of the information from various researchers, the paper has presented those researchers' findings on the issue. The research hypothesis is, 'remedial courses have no effect in increasing the performance of EFL/ESL students.' The research findings indicate that the remedial courses in the Arab universities have been ineffective in increasing English language skills of students learning EFL/ESL.
\end{abstract}

Keywords: Remedial courses, EFL/ESL, Students' performance, Language

\section{Introduction}

Learning one's foreign language is very easy. It comes naturally to the mind and as one gets older, their skills in using the first language increase. This is all the action of the cognitive development in human beings that is the basis of learning. When one starts learning their first language, the skills are acquired through observation and listening to the people around. English is one of the most widely used languages in the world.

The English natives are fluent and eloquent in the use of the language, but those who learn English as a first language or as a second language have problems with different areas in the use of the language. Many a times, the learners have to be taken through short or long courses to learn the appropriate use of the English language. Normally, students joining college in the Arab nations are given remedial courses in English while those looking to master the language are taken through basic skill courses.

Students in some colleges in the Arab region are expected to pass their English tests when they enroll for their college education. This is mainly because most of the teaching in colleges is done by professionals using English. The influence of the western nations on the Arab nations and the rest of the world have prompted the need for students to at least learn basic skills in English. Personal experience has revealed that the effectiveness of remedial teaching of students in their EFL/ESL studies varies.

\section{Purpose of the Study and Research Questions}

The difference in effectiveness may be attributed to the reception of the students in the programs as well as the ability of the students to understand what is taught during the programs. This paper is a descriptive study which looks into how effective the remedial courses are about improving the EFL/ESL student's performance in college. The research paper will highlight the possible causes of low performance in the English language after the remedial courses, highlight the possible solutions to the issue and make a comprehensive conclusion of the hypothesis that remedial courses have no effect on the performance of students.

The paper addresses the following two interrelated questions:

1) How effective are the remedial courses in improving the EFL/ESL student's performance in college?

2) What are the possible causes for the EFL/ESL student's performance after taking the remedial courses required? 


\section{Discussion}

\subsection{Language is not Requisite in their Society}

One of the most important parts of learning English as a foreign or second language is the extent of using it in the daily interactions with other people. This could be simple conversations with the rest of the students or with the remedial course lecturers. A student may also choose to recite some of the words, phrases and sentences learnt in the remedial classes to enhance their comprehension of the language (Sapkota, 2013). This is the basis of learning a foreign or second language. It is the equivalent of a child learning to pronounce words correctly after a long time of practicing with the parents and guardians. In the College setting, the students from the Arab origin are normally not exposed to such scenarios where they have to use the language out of the remedial classes (Moussu, 2010).

Traditionally, the Arab students have been using their native language as the main, if not the only language, to communicate even in the class setting (Malallah, 2000). It gets rather hard for the student to start using English as their default language because of two reasons. First, there are very few students who are ready to engage in the use of English to communicate. The fact that they have an alternative language of communication that is far more efficient makes it difficult for them to use English (El-Dib, 2004). While remedial course lecturers may oblige their students to use the language outside class for practical reasons, the school setting presentsa big challenge to them. Second, the Arabic language is primarily used in the teaching of other courses in the colleges. The students do not get enough exposure to the use of English from other professors apart from those in their remedial classes (Moussu, 2010).

The effectiveness of the remedial courses is also influenced by the negative attitude developed by the students towards the English language (Elmetwally, 2012). Most of the failing students who are enrolled for the remedial courses in EFL/ESL studies are already frustrated by their first failures. Some report to have developed a negative attitude towards the language and this compels them to assume a passive approach to learning it (Tremblay, 2011). They put little or no effort to study it. Some are only motivated to study for their remedial course tests to get over with the course.

\subsection{Lack of Prolonged Exposure}

Many students who undergo a remedial course in EFL/ESL studies finish their course work without improvement in their performance because they are not exposed to practical use of the language outside their lecture halls. The main reason for this is that most of the students start using their native language as soon as they step out of the class rooms. This means that the only time they use English exclusively is when they are in class. Failure to expose the students to the use of English in prolonged periods leads to the erosion of the new ideas that they learn in class (Wang, Shang \& Briody, 2012).

According to the cognitive development theory, the human brain learns a new language by having prolonged exposure to its use (Ilustre, 2011). This can be achieved through listening to other people using the language, reading texts written in the language and having access to the professors to aid them where they fail to comprehend the meaning of words (Ahmed, 2010).The experience should be turned into an enjoyable course where the student has the new things he or she learns, running through his or her mind constantly. This is the kind of environment that lacks in the Arab nations like Kuwait (Bacha \& Bahous, 2011). The use of English as a medium of communication is yet to mature among the students and the professors alike; therefore, the effectiveness of remedial courses in EFL/ESL studies becomes greatly jeopardized with relation to improving the student's performance in English (Wang, Shang \& Briody, 2012).

The use of the English language is based on sets of rules. The tests used by the colleges to measure the skills of students in the language are mainly based on grammar. Remedial lessons acquaint the students with the rules in English on a theoretical context. They ignore the practical use of the language, where the student is supposed to interact with his or her counterparts in the presence of the professors to correct their mistakes. Follow up in the colleges on the part of the lecturers is not comprehensively made to help the student correct their mistakes in the use of the language. It is also quite inappropriate that most of the learning work is done theoretically in books. The students need to converse in the language more as opposed to writing the language (Wang, Shang \& Briody, 2012).

\subsection{Elementary Teaching}

The methods used in the remedial course teaching process are not effective yet the professors continue using them. The cumulative result is a student society with very basic information on the use of the English language. The essence of learning English as a foreign or second language is to fit into a society where the language is used as the primary language of communication. English is an international language that demands from the users to have a good level of expertise in its use to communicate effectively. The remedial courses offered in the colleges focus on delivering the basic learning of the language, which is quite ineffective in helping the students, fit into societies where they have to constantly use the English language (Moussu, 2010). 
Students in the remedial courses for ESL/EFL attend the lectures under pressure because these are additional lessons in their busy schedules. The teaching process is also too basic to capture the attention of some of the students. As Widdison notes, the use of remedial courses has very little positive effect on the performance of students in learning English as a first or second language. This sentiment is derived from the fact that most of the work covered in the remedial classes is similar to the rest of the work covered prior to the enrollment test (Moussu, 2010).

In order to help students improve their performance, the professors need to come up with better teaching strategies that enable the students to cover more work within shorter periods. The exposure of the brain to pressure and constant ideas results in faster learning and easier memorizing of the ideas. The current teaching practices are ineffective in transferring short-term memory to the long-term memory, which is the basis of comprehension of languages (Moussu, 2010).

\subsection{Lack of Students' Seriousness}

The learning of English as a foreign or second language is directly influenced by the purpose of learning in the students. Those who are in the course of a long-term learning process are motivated by their urge to attain professional skills in the English language to study hard. Those who are only in the course to pass their tests, and move on to other major courses in their quest for education fail to put any significant effort in the remedial course. This indicates that the effectiveness of remedial course in the learning process of EFL/ESL studies is directly influenced by the significance of learning the English language. There are students who have no option but to excel in the language while others are just in the remedial course to pass their language test (Wang, Shang \& Briody, 2012).

In the Arab world, education is delivered through the medium of Arabic i.e. he learning material and the lectures are primarily delivered in the Arabic language. This indicates the lack of relevance of the English language to some of the students. Students report having little or no interest in learning the English language based on the fact that most of them seldom use it or pursue it on a professional level. Remedial courses in the language are mainly based on learning the basics of the language. The students are taught how to construct simple sentences and how to apply grammar rules. This learning process is rather hectic and the students feel like it lacks objectives. The results a bored lot of students, who do not enjoy their remedial classes (Wang, Shang \& Briody, 2012).

Lack of participation in classes and leniency in the teaching process is also common in the ESL/EFL studies in colleges around Kuwait. The remedial courses are viewed as punishment for failing the placement tests by the students enrolling in college. With this attitude in their mind, some students fail to give the remedial courses the required attention. Researchers have established that the issue of negative attitude towards language learning is more prominent among the male students (Sunderland, 2000).Lecturers need to develop new teaching strategies that will enhance the performance of the students (Tremblay, 2011).

\subsection{Lack of Motivation}

There is nothing more motivational about sending students to remedial courses even before they get to start studying the main courses they enroll to in the colleges. Most of the students who are sent to the remedial courses claim that it is demoralizing, especially when they are not planning to study the language as part of their mar course. The students further claim that they only engage in the remedial classes to get through to the enrollment process. In the reality, very few students indicate significant improvement in their test results after going through the remedial course in English. It appears that the courses are just a waste of time and since their purpose is seldom served, some feel that the remedial courses should be abolished from the system (Chen, Chen, Chen \& Wey, 2013).

Learning a new language requires patience and the learner should be motivated to continue pushing harder to progress their knowledge in the use of the language. The language learning atmosphere in the Kuwaiti context is quite uninviting for the students because they are literally forced to take up the learning of the English language by the learning institutions (Wu \& Alrabah, 2009). It is an involuntary process that is quite demanding because the students have to grasp a lot of information within a short period of time. Instead of learning the language, most students end up cramming the ideas which they download to the test papers and forget the ideas almost immediately after; they lack the culture of extensive reading (Chen, Chen, Chen \& Wey, 2013).

The interaction between the lecturers and the students in the remedial courses should be very close to attain the required and intended results. For the performance of the students in the English language to improve, the lecturers have to follow up on their performance and motivate them to keep trying to enhance their skills in the language within the short time allocated to remedial courses. The essence of this course is to bring the student closer to someone who can offer him or her, the attention required in learning a first or second language (Chen, Chen, Chen \& Wey, 2013).

One cannot simply grab an English language learning book and start grasping the ideas presented. Most of the lecturers in the colleges treat the students like they already know the basics of the language and, the meaning of 
words; thus, the ineffectiveness of the remedial courses in improving the skills of EFL/ESL students in the language becomes quite conspicuous. The English language skills gathered in the remedial courses are short-lived mainly because the teachers focus on having their student passes his or her test instead of giving them general information (Chen, Chen, Chen \& Wey, 2013).

\subsection{Lack of Standardized Examinations}

Tests in colleges are the traditional measure of the levels of competencies that different students possess. This type of measure has been used in many parts of the world to ensure that the students enrolling for different courses are directed to the relevant course works according to their ability in comprehension. In the Arab countries, the use of tests has been altered into a system of placement based on the skills of the students in using the English language (Troudi, Coombe \& Al-Hamliy, 2009).The students who go through the remedial course feel demoralized because it highlights their inability to comprehend new ideas even before they join the colleges. It is embarrassing to some of the students and it has been sighted as one of the reasons why some students fail to apply for college courses (Wang, Shang \& Briody, 2012).

The nature of the tests offered in different colleges is the testing of basic English language skills. In the past, the tests were simple and objective in determining the actual skills of the students in the language. Many students would pass the tests and get enrolled in the colleges for their respective courses; however, in the recent times, the setting of the questions in the tests is random and very demanding on the part of the students (Wu \& Alrabah, 2009). Despite the efforts they employ in their remedial courses, they still fail or pass with a small margin over the cut off points because the tests are not standardized (Wang, Shang \& Briody, 2012).

\subsection{Teachers Majoring on Specific Parts of Language}

Research has indicated that the language teaching process in the learning institutions is based on giving the students some basic ideas and general rules governing the languages. The students get educated but they lack the wisdom of implementing their acquired skills. For instance, in the process of learning EFL and ESL, students are acquainted with the basic knowledge in the English language. Compared to the English natives, no matter how long the remedial courses take, but the skills in the use of language change insignificantly (Moussu, 2010).

It has been established that the education system in Kuwait and several of the Arab countries is yet to attain the comprehensive state it desires concerning the training of students to use the English language. The teaching syllabus focuses on giving the students textbook skills in the use of the language. The students may perform remarkably on the tests but their usage of language in a practical context is very poor. This indicates that the remedial courses are only suited to enhancing the theoretical part of language learning (Chen, Chen, Chen \& Wey, 2013).

After exploring the vast amount of information presented by various researchers and by analyzing the situation in the Arab Universities, it is quite evident that the remedial courses have failed in their quest. Students continue giving poor results in their skills in the use of the English language. Some professors have indicated their concern on the issue, but an interventional program is yet to be developed. The researchers' findings indicate that the problem lies within the relationship between the lecturers in the remedial classes and the students (Sabeh, Bahous, Bacha \& Nabhani, 2011). They further reveal that the attitude of the students towards the remedial courses is a major factor of their poor performance. The recommendations given hereafter are influenced by the implications of some effective methods that have been used by different people to enhance the performance of the students in their language learning.

\section{Recommendations}

\subsection{Effective Remedial Courses}

In some cases of remedial teaching in the college setting, students have indicated significant progress in their abilities to use English as their first or second language. The effectiveness of the courses is influenced by the implementation of strategic plans in the approach towards instilling permanent language skills in students. Remedial courses, when delivered appropriately, as research indicates, can positively influence significant improvement in the use of language in students (Selvarajan \& Vasanthagumar, 2012). Some of the proven strategies that have indicated an effective influence on the performance of university students in the Arab universities are discussed below.

\subsection{Extensive Studying of Language}

Rigorous coverage of the different areas of the English language that build up the proficiency of students in the use of the language is very important. A study has revealed that students who allocate more hours in their private time to study English by going through their lecture notes record higher performance in their language skills. The students are more fluent in the language and their understanding of the grammar rules is impressive compared to those who only study the language in class. Basic skills in the use of English as a second language can only be instilled in the 
minds of students if they are exposed to prolonged periods of studying the language (Selvarajan \& Vasanthagumar, 2012).

Studying the English language is not only about the theoretical part. It is also good to have the students talking in English and attempting to construct sentences to express themselves. This way, they get to train their brains to start articulating the ideas learnt in class to become proficient in the language. As the old saying goes, practice results to perfection in whatever a person sets his or her mind to do. Critical thinking is important in the cohesion of language ideas in English (Maibodi \& Fahim, 2012). Students with the passion to learn the language through the remedial courses always emerge victorious in their quest, and most of them continue using the language even after the remedial courses are over. They are the students who have effectively fallen out of the monotonous use of the Arabic language exclusively in learning (Selvarajan \& Vasanthagumar, 2012).

\subsection{Strategic Approach to Learning Language}

The trick in the effectiveness of the remedial courses has been identified to lie in the approach that the lecturers use to introduce new ideas to the students. Teachers who move directly to the textbook rules as dictated by the remedial course syllabus notice minimal improvement in their students after the courses (Khan, 2011). Those who develop a more friendly approach to teaching English to EFL/ESL students record more positive influence on their students. In most universities in the Arab world, remedial courses for EFL/ESL students have generally failed to improve the performance of the students, but there are few cases where students excel in the language after the courses (Selvarajan \& Vasanthagumar, 2012). This is attributed to the lecturer's effort integrated with the passion in the students.

A strategic approach is one that is focused on the individual needs of the students. Most of the colleges offered remedial courses that cover specific topics under the guidelines of a school syllabus timetable. These programs only tackle specific areas of the language at a time and this can be discouraging to the students who need help in areas not covered. This ultimately leads to poor performance. Changing this eventuality in improving performance requires for students to be guided in their specific areas of weakness (Al-Tamini \& Shuib, 2009). Lecturers who offer student focused remedial courses are normally graced with the joy of watching their students prosper in the English language after the courses(Strong, Torgerson, Torgerson \& Hulme, 2011).

Students' motivation is also a crucial part in ensuring that the remedial courses are effective in improving the performance of EFL/ESL students. Teachers should develop a teaching strategy that is fun and interesting. Students who learn different languages through the exclusive use of textbooks, as in the case in the Arab universities, seldom record any significant improvement in their use of the respective languages. Some of the most effective approaches that have been used by various lecturers to effectively influence the improvement of the student's performance include the use of music and films as learning material. Supplementary language learning material is very effective in enhancing student's performance (Jonas \& Chwo, 2010). Selecting music that the students enjoy captures their attention and they can learn the words and the rules of the language by evaluating its usage in the music and films. This practical approach is strategic in motivating students to learn via the remedial courses (Selvarajan \& Vasanthagumar, 2012).

\subsection{Simple Short Stories (SSS)}

Students in elementary schools in different parts of the world learn the English language through reading short interesting stories in and out of class. The stories act as a motivational factor in the learning process. They also enable the students to relate certain lessons to the characters in the stories. This approach has been used on Japanese students trying to learn English and the results so far have been remarkable. Researchers looking into the effectiveness of this approach have concluded that the method is very effective in influencing the learningof new languages. Story telling has been established to be quite effective in helping children with learning disabilities with their comprehension in language (Lee, 2012). Some lecturers in the Arab universities have also adopted this teaching method whereby they avail interesting story books to the students and require them to analyze the short stories verbally in class. During this process, the students get to learn the sentence construction rules in English (Strong, Torgerson, Torgerson \& Hulme, 2011).

The SSS is an approach that is designed to captivate the students to learn the new language. It is an approach that has been associated with enhanced comprehension of students in EFL/ESL learning. Reading a short story and understanding the context and plot of the story indicates the level of improvement in students. Through SSS, students can perform self evaluation in learning English (Connerty, 2009). The lecturers can easily pinpoint the areas of weakness in their students by evaluating their comprehension abilities in the simple short stories (Strong, Torgerson, Torgerson \& Hulme, 2011). 


\subsection{Sustained Silent Reading}

The use of simple short stories is very effective in improving students' performance on a short-term basis. Students who fail in their remedial courses have one thing in common; they all do not continue studying through reading outside the remedial classes (Chen, Chen, Chen \& Wey, 2013). Those who indicate improvement spend a lot of their time reading and improving their language in different areas like understanding vocabulary, spelling difficult words, and constructing sentences after reading. Students who develop a reading culture starting with short stories and moving on to longer stories and eventually reading English novels experience great improvement in their language skills. Silent reading for a long time enhances the comprehensive ability of the students (Karim, 2004).

Reading should be voluntary when it comes to learning foreign language. As indicated in the previous sections in this paper, many students fail in their remedial courses because they have no urge to learn the English language beyond the basic level because it does not form an integral part in their major courses. Lecturers who manage to eliminate this lack of interest in learning portrayed by their students help them to improve. The elimination of the mindset that the learning of English in the remedial courses is a punishment takes a strategic approach in teaching (Chen, Chen, Chen \& Wey, 2013).

\subsection{Practicing Language Skills}

Widdison's sentiments on the effectiveness of remedial courses in improving the language skills of EFL/ESL students in the language are not universally true in the Arab universities. Indeed there are students who prosper in the attainment of English skills through the remedial courses. Students who are in the universities to study the language professionally are motivated to keep pushing for prosperity, and the majority of them emerge victorious in their quest. This is normally attained after rigorous practicing of their attained skills in the language amongst their peers (Selvarajan \& Vasanthagumar, 2012).

The Arab colleges and universities have a requirement for the students enrolling for different courses to have good skills in the use of the English language, but most of the universities use Arabic language exclusively. The wise students looking to develop a career in the English language develop learning groups amongst themselves and they engage in discussions aimed at improving their skills (Santiago Sanchez, 2010). The improvement in performance solely rests on the efforts of the students. The lecturers are only there to guide the students but the main effort should emanate from the student's interest in learning. Lecturers who manage to clearly paint this picture for their students witness great improvement in the student's language skills. Personal evaluation in the groups is also a healthy way of helping each other to learn the English language (Selvarajan \& Vasanthagumar, 2012).

\section{Conclusion}

English placement tests in the Arab universities are offered to newcomers as a preparatory test that orients the students to the university education environment. Most students fail in the tests and the universities have come up with a strategic idea to place the students in EFL/ESL learning remedial courses. The courses are aimed at furnishing the students with the basic skills in the English language. Over the years, some professionals offering the remedial courses have claimed that the effectiveness of the courses in improving the skills of students in the foreign language is greatly challenged. Some believe that the remedial courses are just a waste of time for the students because they fail to portray any significant improvement in their test performance. This sentiment is supported by the claims of many students who feel like the remedial courses are a mode of punishment. Their general attitude towards the courses is negative. Others believe that the teaching approach is to blame for the lack of efficiency in remedial courses. Researchers and professors who negate Widdison's sentiment on the issue claim that using the best approaches to teaching students through the remedial courses has recorded positive effects not only in the Arab universities, but also in other parts of the world. Remedial courses for EFL/ESL students should be given a new teaching approach to influence the required results in relation to the skills of the students.

\section{References}

Ahmed, A. H. (2010). Students' Problems with Cohesion and Coherence in EFL Essay Writing in Egypt: Different Perspectives. Literacy Information and Computer Education Journal (LIJEC), 1(4).

Al-Tamimi, A., \& Shuib, M. (2009). Motivation and attitudes towards learning English: A study of petroleum engineering undergraduates at Hadhramout University of Sciences and Technology. GEMA: Online Journal of Language Studies, 9(2), 29-55.

Bacha, N. N., \& Bahous, R. (2011). Foreign Language Education in Lebanon: A Context of Cultural and Curricular Complexities. Journal of Language Teaching and Research, 2(6), 1320-1328. http://dx.doi.org/10.4304/jltr.2.6.1320-1328

Chen, C. N., Chen, S. C., Chen, S. H. E., \& Wey, S. C. (2013). The Effects Of Extensive Reading Via E-Books On Tertiary Level EflStudents' reading Attitude, Reading Comprehension And Vocabulary. Tojet, 12(2). 
Connerty, M. C. (2009). Variation in academic writing among Generation 1.5 learners, native English-speaking learners and ESL learners: The discoursal self of G1. 5 student writers (Doctoral dissertation, University of Birmingham).

El-Dib, M. A. B. (2004). Language learning strategies in Kuwait: Links to gender, language level, and culture in a hybrid context. Foreign Language Annals, 37(1), 85-95. http://dx.doi.org/10.1111/j.1944-9720.2004.tb02176.x

Elmetwally, E. E. (2012). Students' and teachers' attitudes toward the use of learners' mother tongue in English language classrooms in UAE public high schools (Doctoral dissertation, British University in Dubai).

Ilustre, C. A. P. (2011). Beliefs about Reading, Metacognitive Reading Strategies and Text Comprehension among College Students in a Private University. Philippine ESL Journal, 7, 28-47.

Jonas, A., \& Chwo, G. (2010). Adopting supplementary materials to enhance listening and speaking strategy used by Taiwanese college EFL learners. Great Light Journal (59), 25-41.

Karim, K. (2004). Teachers' Perceptions, Attitudes, and Exceptions About Communicative Language Teaching (CLT) in Post-Secondary Education in Bangladesh. Working Papers of the Linguistics Circle, 18(1), 1-12.

Khan, I. A. (2011). Learning difficulties in English: Diagnosis and pedagogy in Saudi Arabia. Educational Research, 2(7), 1248-1257.

Lee, S. Y. (2012). Storytelling Supported By Technology: An Alternative for EFL Children With Learning Difficulties. Tojet, 11(3).

Maibodi, A. H., \& Fahim, M. (2012). The Impact of Critical Thinking in EFL/ESL Literacy. The Iranian EFL Journal, 32(1), 24.

Malallah, S. (2000). English in an Arabic environment: Current attitudes to English among Kuwait university students. International Journal of Bilingual Education and Bilingualism, 3(1), 19-43. http://dx.doi.org/10.1080/13670050008667698

Moussu, L. (2010). Influence of Teacher-Contact Time and Other Variables on ESL Students' Attitudes Towards Native-and Nonnative-English-Speaking Teachers. TESOL Quarterly, 44(4), 746-768. http://dx.doi.org/10.5054/tq.2010.235997

Sabeh, G., Bahous, R., Bacha, N. N., \& Nabhani, M. (2011). A Match or a Mismatch between Student and Teacher Learning Style Preferences. International Journal of English Linguistics, 1(1), p162.

Santiago Sanchez, H. (2010). An investigation into the relationships among experience, teacher cognition, context, and classroom practice in EFL grammar teaching in Argentina (Doctoral dissertation, University of Warwick).

Sapkota, A. (2013). Developing Students' Writing Skill through Peer and Teacher Correction: An Action Research. Journal of NELTA, 17(1-2), 70-82. http://dx.doi.org/10.3126/nelta.v17i1-2.8094

Selvarajan, P. \& Vasanthagumar, T. (2012). The Impact of Remedial Teaching on Improving the Competences of Low Achievers. International Journal of Social Science \& Interdisciplinary Research, 1(9), 49-59.

Strong, G. K., Torgerson, C. J., Torgerson, D., \& Hulme, C. (2011). A systematic meta-analytic review of evidence for the effectiveness of the 'Fast For Word' language intervention program. Journal of Child Psychology and Psychiatry, 52(3), 224-235. http://dx.doi.org/10.1111/j.1469-7610.2010.02329.x

Sunderland, J. (2000). Issues of language and gender in second and foreign language education. Language Teaching, 33(4), 203-223. http://dx.doi.org/10.1017/S0261444800015688

Tremblay, P. (2011). Assessment of the Real and Perceived Effectiveness of Two Educational Models for Students with Learning Disabilities. Literacy Information and Computer Education Journal, 2(1), 277-284.

Troudi, S., Coombe, C., \& Al-Hamliy, M. (2009). EFL Teachers' Views of English Language Assessment in Higher Education in the United Arab Emirates and Kuwait. TESOL Quarterly, 43(3), 546-555.

Wang, Y. J., Shang, H. F., \& Briody, P. (2012). Exploring the impact of using automated writing evaluation in English as a foreign language university students' writing. Computer Assisted Language Learning, (ahead-of-print), 1-24. http://dx.doi.org/10.4018/ijcallt.2012070101

Wu, S. H., \& Alrabah, S. (2009). A cross-cultural study of Taiwanese and Kuwaiti EFL students' learning styles and multiple intelligences. Innovations in Education and Teaching International, 46(4), 393-403. http://dx.doi.org/10.1080/14703290903301826 